Original Paper http://ajol.info/index.php/ijbcs http://indexmedicus.afro.who.int

\title{
Protective effect of phenylalanine and glycine on chloramphenicol-induced bone marrow toxicity in albino rats infected with Klebsiella Pneumoniae
}

\author{
A.C. ENENDU ${ }^{1 *}$, P.C. UNEKWE ${ }^{2}$, C.O. ESIMONE ${ }^{3}$, E. OBI $^{2}$ and K.C. CHILAKA ${ }^{2}$ \\ ${ }^{1}$ Department of Human physiology, Nnamdi Azikiwe University Awka Anambra State Nigeria. \\ ${ }^{2}$ Department of Pharmacology and Therapeutics, Nnamdi Azikiwe University Awka Anambra State Nigeria. \\ ${ }^{3}$ Department of Pharmaceutics, Nnamdi Azikiwe University Awka Anambra State Nigeria. \\ *Corresponding author; E-mail: angechik2010@gmai.com; Tel +2348039364001.
}

\begin{abstract}
The effect of phenylalanine and glycine on chloramphenicol (CAP) induced bone marrow toxicity in albino rats infected with Klebsiella pneumoniae was investigated. The aim was investigate whether the treatment of the infected rats with either of these amino acids or their combination could reverse the major bone marrow toxicity of CAP. The study lasted for a period of 21 days in which haematological and histopathological changes were monitored in the infected rats. After 7 days, the rats became anaemic after treatment with CAP, but amino acids combined groups suppressed the anaemia and infection to some extent. At the end of 21 days, amino acids combination showed significant $(\mathrm{p}<0.05)$ suppression of anaemia except in CAP/Phenylalanine/glycine (group 4). Bone marrow examination showed the mechanism involved in the suppression of anaemia ( amino acids administration triggered RBC compensatory mechanism seen as erythroid hyperplasia and myeloid hypoplasia ). Histopathology changes ranges from hypocellularity in $\mathrm{CAP}$ group and fairly normocellularity in $\mathrm{CAP} /$ phenylalanine, $\mathrm{CAP} /$ glycine and necrotic/degenerative changes in group 4. Single amino acids combination with CAP have obvious protective effect and suppressed the bone marrow toxicity of CAP compared to the combination of the two amino acids with CAP, but all the combinations were effective in enhancing the efficacy of CAP.

(C) 2016 International Formulae Group. All rights reserved.
\end{abstract}

Keywords: Chloramphenicol toxicity, haematoxicity, amino-acids.

\section{INTRODUCTION}

Chloramphenicol (CAP) is an old antibiotic that came into clinical practice in 1949. It is a popular broad spectrum antibiotic, because of its high antimicrobial activity against Gram positive and Gram negative bacteria, Chlamydia, Rickettsia and Mycoplasia. It is a potent bacteriostatic antibiotic that is particularly useful in infections caused by Salmonella typhi, meningitides and Heamophillus influenza
(Fullers et al., 2003; Chambers, 2006; Dowling, 2006). The adverse effect of CAP is mainly haematological : aplastic anaemia (Turton et al., 2002 ; Rosenberg and Marcus, 2008; Clark and Kumar, 2011; McCurdy, 2011), bone marrow suppression (Clark and Kumar., 2011), hypersensitivity reactions includes optic neuropathy, skin reaction (Chambers, 2006). CAP is one of the common drugs that causes pancytopenia (Chen, 2005). It is the major problem of this 
drug worldwide. Despite the bann placed on the use of the drug because of these haematoxic and other adverse effects, the drug continues to be used in many part of the world because of its availability and cost effectiveness over the newer antibiotic (Ruef and Blaser, 2000). Nevertheless, the global problem of advancing bacterial resistance to newer drugs has led to review interest in its use (Falagas et al., 2008). Studies done by Effiong et al. (2010), Hossam et al. (2010) among others was effective in reducing the toxic effect of CAP but the efficacy was affected. Exception was seen in the study done by Chilaka et al. (2005) and Esimone et al. (2007). Their study improved on the antibacterial effect of the drug because they used amino acids, Chilaka et al. (2005) worked on peripheral blood only while Esimone et al. (2007) study the effects on peripheral blood and organs (liver and spleen). Their studies were not extended to the bone marrow where there is major toxicity. These amino acids (phenylalanine and glycine) were effective because they were found to have protective and antibacterial effect. Their protective effects were confirmed by the studies of (Asakhiors et al., 2000; Yin et al., 2002; Zhou et al., 2005; Senthikumar et al., 2004; Para-vizuet et al., 2009; Yolande et al., 2011; Ponjit et al., 2011; Manion et al., 2011), while their antibacterial effect were supported by the studies of Minami et al., 2004; Sharma et al., 2012). Due to the limitations of most of the CAP toxicity reduction studies above and to sustain the therapeutic value of CAP in specific indications especially in developing countries, we decided to carry out study directly on bone marrow with the aim to study the effects of phenylalanine (an hydrophobic aromatic ring amino acid) and glycine (an hydrophilic straight chain amino acids) on haematological and histopathological profile of CAP- induced bone marrow toxicity in albino rats infected with Klebsiella pneumoniae.

\section{MATERIALS AND METHODS \\ Preparation of inoculum \\ The test organism Klebsiella} pneumoniae was purified after gram staining by streaking in sterile nutrient agar plates. Maintenance and cultivation of the organism were carried out by weekly subculturing on different nutrient agar slants. The agar slants were stored in a refrigerator at $4{ }^{\circ} \mathrm{C}$ after 24 hrs incubation at $37{ }^{\circ} \mathrm{C}$. The organism was activated before use by successive subculturing in $10 \mathrm{ml}$ sterile nutrient agar slant for 3 consecutive days. In each case ,the inoculum was usually $24 \mathrm{hrs}$ old culture of Klebsiella pneumoniae, standard inoculum size of $0.5 \times 10^{6} \mathrm{CFUf} / \mathrm{ml}$ (Mc Farland) was used for the test.

\section{Animal and experimental design}

Thirty albino rats of about two-three months weighing of about 90-120 g were obtained from the animal house of the pharmaceutical science, Nnamdi Azikiwe University (Unizik) Agulu branch, they were acclimatized in pharmacology laboratory for one week before the beginning of the experiment. They were fed with commercial growers feed, also they had access to clean drinking water. The animals were randomly divided into five groups of each comprising 4 test groups and 1 control groups containing six animals each. Infection of Klebsiella pneumoniae was induced by single intraperitoneal injection of $0.5 \mathrm{ml}$ of freshly prepared inoculum of Klebsiella pneumoniae in normal saline to all the groups, followed immediately by the intraperitoneal administration of the following. Group 1: $5.0 \mathrm{mg} / \mathrm{kg}$ bw of chloramphenicol (CAP) only;

Group 2: $5.0 \mathrm{mg} / \mathrm{kg}$ bw of CAP $+2.0 \mathrm{mg} / \mathrm{kg}$ bw of phenylalanine;

Group 3: $5.0 \mathrm{mg} / \mathrm{kg}$ bw of CAP $+5.0 \mathrm{mg} / \mathrm{kg}$ bw of glycine;

Group 4: $5.0 \mathrm{mg} / \mathrm{kg} / \mathrm{bw}$ of CAP $+2.5 \mathrm{mg} / \mathrm{kg}$ bw of phenylalanine $+5.0 \mathrm{mg} / \mathrm{kg}$ bw of glycine Group 5: no treatment (control). 
Drug dilutions were made with sterile normal saline. The animals were observed daily for disease or any overt sign of toxicity. On the $21^{\text {st }}$ day, the survivors were sacrificed and monitored histopathologically.

\section{Collection of blood}

Blood for haematological examination was collected by ocular puncture: each animal was anesthetized with diethylether using heparinised capillary tubes, blood flows from retinal vein directly into plastic tubes containing EDTA (ethylenediaminetetraacetic acid). Blood samples was collected three times for haematological analysis which include blood for pre-treatment test (day zero), on the $7^{\text {th }}$ and $21^{\text {st }}$ days post treatment.

\section{Haematological /Histopathology analysis}

Haematological analysis were carried out using the following methods: Pack cell volume (PCV) and haemoglobin concentration (HB) were determined by microhaematocrit and sahli methods respectively. Reticulocyte count were determined by supravital staining techniques using New methylene blue stain also leishman stain was used for White blood cell differential count. Reticulocyte index (RI) was calculated by multiplying reticulocytes counted with PCV and divide by HB. Total White blood cell count was done using hemocytometer method. They were determined according to the standard methods described earlier (Cheesebrough., 2002). Bone marrow aspirates was stained with leishman stain followed by bone marrow differential count and calculation of myeloid erythroid ratio. The survival animals were sacrificed on the $21^{\text {st }}$ day, sections of the bones were fixed in $10 \%$ formalin for $24 \mathrm{hrs}$ for bone marrow histopathological analysis which involved the following stages decalcification, paraffin embedded, hematoxylin and eosin (H\&E) stained section of the bone marrow.

\section{Statistical analysis}

The results of this study were analysed using Salstat-statistical package 2, in which all the results were expressed as mean \pm standard deviation of mean (SDM) and Student t-test and hypothetical test was used to assess statistical significance in various groups of animals. Differences in paired mean observation were regarded as significant at $\mathrm{p}<0.05$.

\section{RESULTS}

It was observed that two out of the four animals in group 5 (infected but not treated) died before the $7^{\text {th }}$ day. The following pattern of death were recorded in the test groups: group1: (1), group 2: (1), group $3:$ (1) group $4:$ (2). The haematological indices on the $7^{\text {th }}$ day indicated that there was decrease in packed cell volume (PCV), haemoglobin (HB) , reticulocyte count and reticulocyte index (RI) and these values were statistically different from pre-treatment values ( $\mathrm{p}$ $<0.05)$. In contrast, there was increase in WBC total count which was not significant $(p>0.05)$ in the test groups. There was significant $(\mathrm{p}<0.05)$ lymphocytosis and neutropenia in WBC differential count of $\mathrm{CAP}$ alone and $\mathrm{CAP} /$ phenylalanine /glycine groups, also, there was neutrophilia in the control groups. The blood picture report showed the presence of hypochromic RBC and thrombocytopenia in group 1 and 4 (Tables 1 and 2). The result of haematological indices on day 21 compared to that on the $7^{\text {th }}$ day indicated that there was significant $(\mathrm{p}<0.05)$ increase in RBC haematological indices in all the groups except in group 1 (CAP alone) and 4 (CAP/phenylalanine/glycine). In contrast the increase in WBC was controlled on the $7^{\text {th }}$ day by the test groups, therefore there was no significant $(\mathrm{p}>0.05)$ decrease on the $21^{\text {st }}$ day. There was significant $(p<0.05)$ decrease in lymphocytes in WBC differential count, returning the blood picture to normal except in group 1 and 4 that had persistent neutropenia (Table 3). The result of haematological examination of bone marrow 
showed that there was erythroid hyperplasia and myeloid hypoplasia in all the groups except in CAP group that had severe erythroid hypoplasia of -13 of $26.5(-50 \%)$. There was general decrease in myeloid erythroid ratio in all the groups, but it was severe in group 1 and 4 (Table 4).

Histopathology result of bone marrow in group 1 showed that there is no significant changes in the bone marrow architecture, but there was moderate to severe haematopoiesis with subsequent increased adipocytes that resulted to hypocellularity signifying the presence of aplastic anaemia. In group 2, there is also no significant changes in the bone marrow architecture, but there was moderate to less severe haematopoiesis with decreased adipocytes that resulted to fairly normocellularity. CAP/ glycine group, the picture shows that there was clotted bone marrow, a sign that healing process had commenced resulting to fairly normocellularity. In CAP/phenylalanine /glycine group the bone marrow picture showed that there was a degenerative/necrotic change with complete distortion of bone marrow architecture. Finally, the Control group showed that there was normal bone marrow with normal distribution and cellularity, also several distinct megakaryocytes can be recognized because of their large size and multiple nuclear lobes (Figures 1-5).

From the above results, the potency of the drug used in the treatment was analysed, that of anaemia was evaluated by noting the dose of the drugs that caused percentage decrease after 7 days and increase after 21 days in RBC haematological indices. It was observed that the treatment that caused high increase after 21 days had compensatory effect on RBC that was initially decreased by chloramphenicol administration after 7 days. These observations was confirmed by the increase of $122.6 \%$ erythroid hyperplasia and histopathology changes. Therefore, treatment in group 2 (5mg of CAP $+2.5 \mathrm{mg}$ of phenylalanine) was most potent followed by group 3 (5mg of CAP $+5 \mathrm{mg}$ of Glycine) with $90.5 \%$, while treatment in group 1 and 4 was not potent (Table 5). Potency of drug used in the treatment of infection was also evaluated by noting the dose that caused increase effect after 7 days and decrease effect after 21 days on WBC total count. It was observed that the treatment with less increase effect and high decrease effect on WBC count were more potent, therefore, group 3 was most potent followed by group 1. Finally, group 4 was the least potent (Table 6).

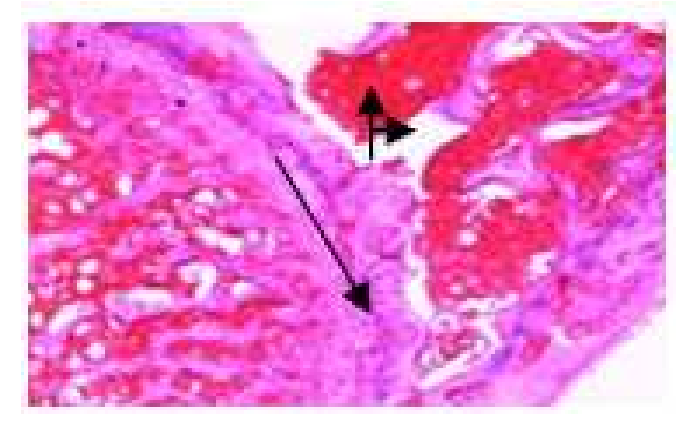

Figure 1: (Bone marrow photomicrograph of group 1). Top arrowhead pointing at areas of hypocellularity and increased adipocytes (whitish) signifying the presence of aplastic anaemia. Down arrowhead is pointing at the section of bone. 


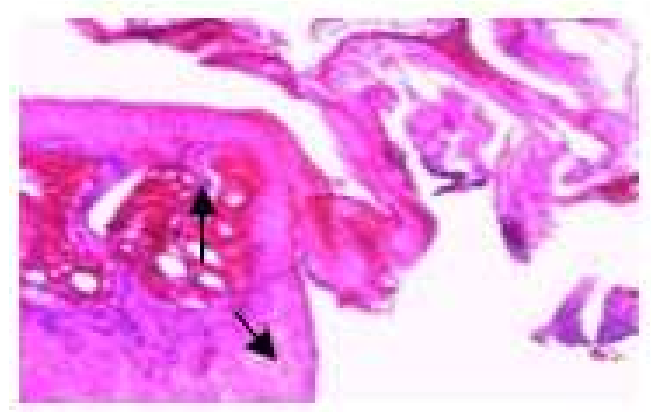

Figure 2: (Bone marrow photomicrograph of group 2). The arrowhead pointing at area of moderate to less severe haematopoiesis with decrease adipocytes resulting to fairly normocellularity.

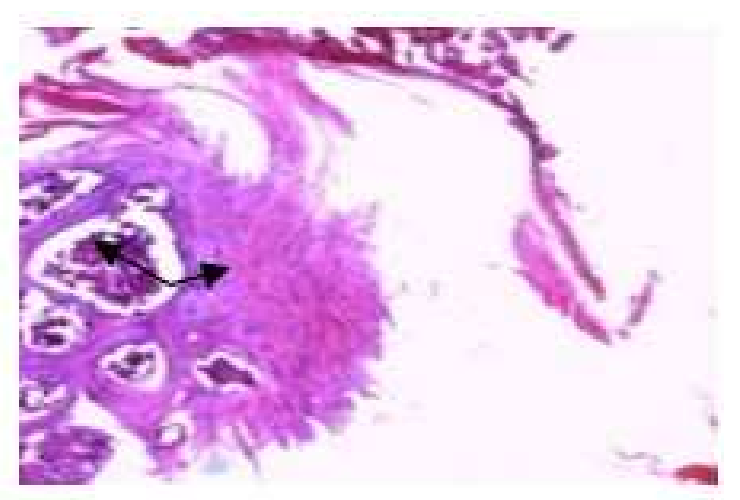

Figure 3: (Bone marrow photomicrograph of group 3).The arrowhead is pointing at clotted bone marrow resulting to healing to fairly normocellularity.

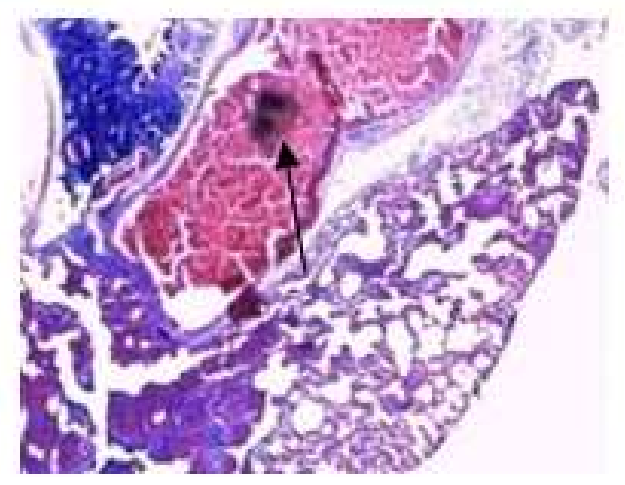

Figure 4: (Bone marrow photomicrograph of group 4). The arrowhead is pointing at area of degenerative/necrotic changes. 
A.C. ENENDU et al. / Int. J. Biol. Chem. Sci. 10(1): 369-383, 2016

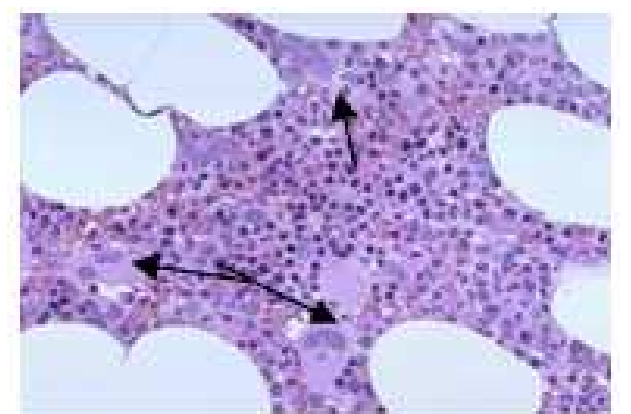

Figure 5: (Bone marrow photomicrograph of control group). Top arrowhead is pointing at areas of normal distribution and cellularity. Bottom arrowhead pointing at two megakaryocytes.

Table1: Pre-treatment (baseline) haematological data.

\begin{tabular}{|c|c|c|c|c|c|}
\hline Groups & 1 & 2 & 3 & 4 & 5 \\
\hline Mean wt (kg) & 94.9 & 116.5 & 98.0 & 111.0 & 109.7 \\
\hline $\operatorname{PCV}(\%)$ & $73.0 \pm 6.00$ & $69.0 \pm 7.21$ & $69.5 \pm 4.55$ & $64.0 \pm 5.74$ & $64.5 \pm 6.31$ \\
\hline $\mathrm{HB}(\mathrm{g} / \mathrm{ml})$ & $24.3 \pm 3.02$ & $23.1 \pm 4.74$ & $21.3 \pm 4.53$ & $21.6 \pm 3.01$ & $21.6 \pm 6.31$ \\
\hline Reticulocyte count (\%) & $1.79 \pm 1.28$ & $1.77 \pm 0.01$ & $1.53 \pm 0.05$ & $1.15 \pm 2.05$ & $1.37 \pm 2.52$ \\
\hline Reticulocyte index & $2.90 \pm 2.47$ & $2.71 \pm 0.32$ & $2.39 \pm 0.39$ & $1.63 \pm 3.12$ & $2.07 \pm 0.12$ \\
\hline WBC total count $\left(\times 10^{3}, 10^{2}\right)$ & $6.48 \pm 1.92$ & $6.67 \pm 8.30$ & $6.83 \pm 8.30$ & $6.90 \pm 7.07$ & $6.75 \pm 1.12$ \\
\hline Neutrophils & $67.0 \pm 9.89$ & $66.0 \pm 0.40$ & $65.0 \pm 2.05$ & $67.0 \pm 7.87$ & $60.7 \pm 5.53$ \\
\hline Lymphocytes & $32.0 \pm 5.29$ & $34.0 \pm 1.89$ & $35.0 \pm 1,94$ & $33.0 \pm 1.87$ & $39.0 \pm 5.53$ \\
\hline Blood picture report (platelets/RBC) & Adequate/Normal & Adequate/Normal & Adequate/Normal & Adequate/Normal & Adequate/Normal \\
\hline
\end{tabular}


Table 2: Effect of administration of phenylalanine and glycine on CAP induced bone marrow toxicity in rats infected with Klebsiella pneumoniae.

\begin{tabular}{|c|c|c|c|c|c|}
\hline Treatment & CAP & CAP /Pheln & CAP/glycine & CAP/pheln/glycine & No Treatment \\
\hline $\mathrm{PCV}(\%)$ & $39.0 \pm 2.64(-46.5)$ & $40.3 \pm 3.61(-41.5)$ & $43.0 \pm 2.44(-38.1)$ & $34,5 \pm 0.05(-46.0)$ & $35.0 \pm 2.15(-45.7)$ \\
\hline $\mathrm{HB}(\mathrm{g} / \mathrm{ml})$ & $13.3 \pm 1.41(-46.5)$ & $13.4 \pm 1.00(-41.6)$ & $14.3 \pm 1.23(-38.0)$ & $11.5 \pm 0.16(-46.0)$ & $11.6 \pm 0.69(-46.1)$ \\
\hline Reticulocyte count (\%) & $0.22 \pm 0.10(-87.9)$ & $0.73 \pm 0.36(-58.8)$ & $0.86 \pm 0.19(-44.5)$ & $0.24 \pm 0.06(-79.7)$ & $0.57 \pm 0,03(-60.7)$ \\
\hline Reticulocyte index & $0.19 \pm 1.41(-92.9)$ & $65.0 \pm 0.72(-76.0)$ & $0.82 \pm 0.14(-64.0)$ & $0.18 \pm 0.05(-88.9)$ & $0.44 \pm 0.06(-78.7)$ \\
\hline WBC total count $\left(\mathrm{x} 10^{3}\right.$ & $6.80 \pm 1.07(+14.9)$ & $8.70 \pm 8.30(+30.0)$ & $7.20 \pm 4.30(+5.40)$ & $8.20 \pm 8.00(+18.8)$ & $18.8 \pm 1.48(+178)$ \\
\hline Neutrophil & $24.0 \pm 4.90(-58.0)$ & $38.0 \pm 5.71(-42.0)$ & $49.0 \pm 5.71(-24.6)$ & $35.0 \pm 4.24(+47.7)$ & $78.0 \pm 3.50(+98.0)$ \\
\hline Lymphocytes & $76.0 \pm 4.90(+132)$ & $62.0 \pm 5.71(+82.0)$ & $51.0 \pm 5.71(+45.7)$ & $65.0 \pm 4.24(+96.9)$ & $22.0 \pm 3.56(-63.0)$ \\
\hline Blood picture report Platelet/ RBC & Thrbcp/hypochm & Adequate/hypocm & Adequate/hypochm & Thrbcp/hypochm & Adequate/hypochm \\
\hline
\end{tabular}

(Significant $\mathrm{p}<0.05$,values in parenthesis represents percentage decrease (-) or increase (+) in respective indices on the $7^{\text {th }}$ day in relative to pre-treatment data.). Thrbcp $=$ Thrombocytopenia Pheln= Phenylalanine, hypochm =hypochromic. 
Table 3: Effect of administration of amino acids (phenylalanine and glycine on chloramphenicol (CAP) induced bone marrow toxicity in rats infected with Klebsiella pneumoniae on the $21^{\text {st }}$ day.

\begin{tabular}{llllll}
\hline Groups & $\mathbf{1}$ & $\mathbf{2}$ & $\mathbf{3}$ & $\mathbf{4}$ & $\mathbf{5}$ \\
\hline PCV $(\%)$ & $44.5 \pm 3 . .64$ & $43.0 \pm 1.20$ & $40.0 \pm 6.48$ & $38.0 \pm 6.04$ & $43.0 \pm 0.18$ \\
HB $(\mathrm{g} / \mathrm{ml})$ & $14.8 \pm 1.20$ & $14.3 \pm 1.26$ & $13.3 \pm 2.16$ & $12.6 \pm 2.60$ & $14.3 \pm 0.18$ \\
Average $\% \Delta$ in PCV/ HB & $(+13.0)$ & $(+6.73)$ & $(-6.98)$ & $(+9.85)$ & $(+23.0)$ \\
Reticulocyte count $(\%)$ & $0.26 \pm 2.06(+18.1)$ & $1.36 \pm 0.10(+95.3)$ & $1.32 \pm 0.04(+53.4)$ & $0.27 \pm 1.97(+20.8)$ & $1.45 \pm 0.02(+140)$ \\
Reticulocyte index & $0.25 \pm 3.07(+31.5)$ & $1.29 \pm 0.54(+98.4)$ & $1.17 \pm 0.37(+42.6)$ & $0.24 \pm 4.03(+33.3)$ & $1.31 \pm 0.14(+197)$ \\
WBC total count $\left(\mathrm{x} 10^{3}\right.$ & $4.36 \pm 6.10(-35.8)$ & $8.40 \pm 1.50(-3.40)$ & $4.80 \pm 5.09(-33.0)$ & $7.40 \pm 1.85(-9.70)$ & $16.0 \pm 1.73(-\mathrm{II} .7)$ \\
Neutrophil & $56.0 \pm 8.92$ & $62.0 \pm 0.48$ & $74.0 \pm 2.01$ & $58.0 \pm 8.02$ & $55.0 \pm 4.69$ \\
Lymphocytes & $49.0 \pm 4.24$ & $36.0 \pm 848$ & $24.0 \pm 7.48$ & $38.0 \pm 4.24$ & $44.0 \pm 6.92$ \\
Blood Picture Report & Thrbcp/Normal & Adequate/Normal & Adequate/Normal & Thrbcp/Normal & Adequate/Normal \\
Platelet/ RBC & & & & & \\
\hline
\end{tabular}

(Significant $\mathrm{p}<0.05) \%$ increase (+) in PCV/HB, Reticulocyte count and Reticulocytes index (index for amelioration of anaemia) and decrease (-) in WBC count (index for remission of infection) on the $21^{\text {st }}$ relative to the $7^{\text {th }}$ day. 
Table 4: Effect of administration of phenylalanine and glycine on bone marrow count of survival rats after 21 days.

\begin{tabular}{|c|c|c|c|c|c|}
\hline Groups & 1 & 2 & 3 & 4 & 5 \\
\hline \multicolumn{6}{|l|}{ MYELOID CELLS } \\
\hline WBC Blast : NV(56.5\%) & $17.0 \pm 4.24(-70.0)$ & $30.0 \pm 6.16(-47.0)$ & $34.0 \pm 5.65(-39.8)$ & $30.0 \pm 2.82(-47.0)$ & $40.0 \pm 6.16(-29.2)$ \\
\hline RMKS & Svr myeloid hypla & Myeloid hypoplasia & Myeloid hypoplasia & Myeloid hypoplasia & Myeloid hypoplasia \\
\hline Eosinophils & $35.0 \pm 7.60$ & $27.0 \pm 6.00$ & $28.0 \pm 7.48$ & $26.0 \pm 5.65$ & $24.0 \pm 6.80$ \\
\hline Basophils & $14.0 \pm 4.60$ & $1.0 \pm 2.24$ & $2.0 \pm 2.44$ & $14.0 \pm 3.30$ & $3.0 \pm 2.41$ \\
\hline Monocytes & $6.0 \pm 3.20$ & $4.0 \pm 3.00$ & Nil & Nil & Nil \\
\hline Total & 100 & 100 & 100 & 100 & 100 \\
\hline \multicolumn{6}{|l|}{ ERYTHRIOD CELLS } \\
\hline RBC Blast NV :(25.6\%) & $12.0 \pm 3.60(-50)$ & $57.0 \pm 3.74(+122.6)$ & $50.0 \pm 2.82(+90.5)$ & $27.0 \pm 4.24(+5.40)$ & $60.0 \pm 4.89(+134)$ \\
\hline RMKS & Svr erythroid hypla & Erythroid hyperpla & Erythroid hyperplasia & Erythroid hyperplasia & Erythroid hyperplasi \\
\hline M.E Ratio & $1.4: 1.0$ & $1.0: 1.9$ & $1.0: 1.5$ & $1.1: 1.0$ & $1.0: 1.5$ \\
\hline
\end{tabular}


Table 5: Evaluation of potency of the drug used in treatment of bone marrow suppression and aplastic anaemia.

\begin{tabular}{|c|c|c|c|c|}
\hline Treatment & CAP & CAP/Phenylalanine & CAP/glycine & CAP/Phenyl/glycine \\
\hline Dose (mg) & $(5.0)$ & $(5.0+2.5)$ & $(5.0+5.0)$ & $(5.0+2,5+5.0)$ \\
\hline \multicolumn{5}{|c|}{ \% Decrease in RBC IND after 7 days } \\
\hline $\mathrm{PCV} / \mathrm{HB}$ & $-(46.6)$ & $-(41.6)$ & $-(38.1)$ & $-(46.0)$ \\
\hline Reticulocyte count & $-(87.7)$ & $-(58.7)$ & $-(44.5)$ & $-(79.1)$ \\
\hline Reticulocyte index & $-(93.4)$ & $-(76.0)$ & $-(64.0)$ & $-(88.9)$ \\
\hline \multicolumn{5}{|c|}{$\%$ Increase in RBC 1ND after 21days } \\
\hline $\mathrm{PCV} / \mathrm{HB}$ & $+(14.1)$ & $+(6.71)$ & $+(-6.89)$ & $+(9.85)$ \\
\hline Reticulocyte count & $+(18.1)$ & $+(97.3)$ & $+(53.4)$ & $+(20.8)$ \\
\hline Reticulocyte index & $+(31.5)$ & $+(98.4)$ & $+(42.6)$ & $+(33.3)$ \\
\hline$\%$ Decrease in Myeloid cell & $-(70.0)$ & $-(47.0)$ & $-(38.9)$ & $-(47.0)$ \\
\hline$\%$ Increase in Erythroid cell & $+(-50.0)$ & $+(122.6)$ & $+(90.5)$ & $+(5.40)$ \\
\hline Potency & Not potent & Most potent & S S potency & Not potent \\
\hline
\end{tabular}

Less percentage decrease ( - ) after 7 days and high percentage increase (+ ) after 21days in RBC indices, followed by high \% increase (+) of erythroid cells (hyperplasia). ( an index for greater potency in amelioration of aplastic anaemia and bone marrow suppression ). SS = Slow and Steady, IND=Indices.

Table 6: Evaluation of potency of the drugs used in the treatment of Klebsiella pneumoniae.

\begin{tabular}{|c|c|c|c|c|}
\hline Treatment & CAP & CAP/Phenylalanine & CAP/glycine & CAP/Phenyl/glycine \\
\hline Dose (mg) & $(5.0)$ & $(5.0+2.5)$ & $(5.0+5.0)$ & $(5.0+2.5+5.0)$ \\
\hline$\%$ Increase in $\mathrm{WBC}$ after 7 days & $+(14.0)$ & $+(30.0)$ & $+(5.40)$ & $+(18.8)$ \\
\hline$\%$ Decrease in WBC after 21 days & $-(35.8)$ & $-(3.40)$ & $-(33.0)$ & $-(9.70)$ \\
\hline Remarks & Potent with fast action & Potent with slow action & Potent with very fast action & Potent with slow action \\
\hline
\end{tabular}

Remarks

Potent with fast action

Potent with slow action

Potent with very fast action

Potent with slow action

Less percentage increase (+) after 7 days and high percentage decrease (--) after 21 days in WBC total count. (Index for greater potency in remission of infection of Klebsiella pneumoniae). Phenyl = Phenylalanine. 


\section{DISCUSSION}

In CAP treated group, there was anaemia, reticulocytopenia and decrease reticulocyte index, evident that there was general decrease in overall erythroid activity (in peripheral blood and bone marrow) after 21 days. Severe erythroid hypoplasia and myeloid hypoplasia in bone marrow aspiration count, followed by neutropenia, and thrombocytopenia in the blood picture confirmed pancytopenia (a feature of aplastic anaemia) in the group, supported by the findings of Chen (2005); Clark and Kumar (2011). Histopathology result of hypocellularity in the group confirmed the findings that CAP causes aplastic anaemia (Rich et al., 1950; Daum et al., 1997; Holt and Bajoria, 1999; Turton et al., 2002; Smick et al., 2004; Chen, 2005; McCurdy, 2011). $\mathrm{CAP} / \mathrm{Phenylalanine}$ combination was able to control anaemia caused by CAP administration. Bone marrow count of increased erythroid hyperplasia of $122 \%$ showed that phenylalanine administration triggered RBC compensatory mechanism to supress the anaemia caused by CAP, and finally histopathology result of fairly normocellularity, correlates with earlier study that phenylalanine reverses the toxic effect of CAP (Ingall et al., 1965) . Studies by (Zhou et al., 1997 ; Ichiyama et al., 1999; Askhiors et al., 2000 ; Manion et al., 2011) also confirmed the protective effects of phenylalanine. CAP/glycine combination also was able to control anaemia caused by CAP administration, concurrent administration produced negligible percentage difference in the red cell indices on day 21 when compared with the values obtained on day 7. This shows that the ability of the combination to control anaemia peaked on day 7 and remained almost constant till day 21. Bone marrow erythroid hyperplasia of
90.5\% showed that glycine also triggered RBC compensatory mechanism to supress the anaemia. Its slow and steady action was confirmed by the clotting mechanism it uses to return to fairly normocellularity in histopathology result. These findings confirmed the protective effect of glycine, that was earlier supported by the studies of (Zhou et al., 1997 ; Jacob et al., 2003; Senthilkumar et al., 2004; Para-vizuet et al., 2009; Ponjit et al., 2011). The mechanism of protective effects of glycine is partially explained by glycine inhibitory effect it can hyperpolarized certain immune cells via glycine gated chloride channels decreasing the amount of toxic mediated (TNT- $\alpha, 1 \mathrm{~L}-6$ ) release in response to endotoxin and other stimuli (Froh et al., 2002). In $\mathrm{CAP} /$ phenylalanine/glycine combination, the histopathology result of degenerative/necrotic changes confirmed the persistent bone marrow suppression, decreased RBC compensatory effect of 5,4\% erythroid hyperplasia and neutropenia. The $5.4 \%$ erythroid hyperplasia showed that the combination have little effect on suppression of anaemia, which was supported by the findings of (Chilaka et al., 2005; Esimone et al., 2007). This finding further explain the fact that chloramphenicol interferes with the folic acid uptake thereby inducing anaemia but glycine and phenylalanine combination with CAP play a role in increasing the folate carrier and thereby reducing anaemia (Tse et al., 1998). The histopathology findings explained that the combination can only suppress anaemia at the peripheral blood level but could not protect the bone marrow, which was supported by the findings of Esimone et al. (2007) that the combination did not protect the blood forming organs : (liver and spleen) as their histopathology section showed degeneration /necrotic changes and congested 
red pulp with moderate to severe haemosiderosis respectively. The ability of the above mentioned combinations (CAP/phenylalanine, CAP/glycine and $\mathrm{CAP} /$ phenylalanine/ glycine) to control progression of infection of Klebsiella pneumoniae peaked on the day 7 till day 21 , their ability to do so was confirmed with result of statistical analysis of no significant increase $(\mathrm{p}>0.05)$ in WBC total count. $\mathrm{CAP} /$ glycine was most remarkable in the control of infection which was supported by the fact that glycine have antibacterial effect (Hishinuma et al., 1970 ; Tomoeda, 1976; Minami et al., 2004) . The proposed mechanism by which glycine increase the antibacterial activity of CAP is as a result of its ability to inhibits the synthesis of a peptidoglycan component of the bacterial cell wall (Minami et al., 2004) . Based on the mechanism, glycine produce synergistic effect when combined with CAP, thereby increase its antibacterial effect. CAP / phenylalanine combination antibacterial effect was supported by the finding of (Cockburn et al., 1965; Sharma et al., 2012). The finding of Sharma et al. ( 2012) states that phenylalanine (a peptide drug) produce synergistic effect when combined with nonpeptide drug and can be used to battle increasingly drug- resistant microbes. Based on the finding of Sharma et al. (2012), CAP (a non-peptide drug) combined with Phenylalanine (a peptide drug) produced increase effect; this might be the proposed mechanism of phenylalanine increased antibacterial effect with CAP.

\section{Conclusion}

The result of the study showed that CAP causes anaemia (bone marrow suppression and aplastic anaemia) but the combination with phenylalanine or glycine caused reduction in all the bone marrow toxic effects while combination of the two amino acids with CAP have very significant effect only in peripheral blood in reduction of anaemia. All the combinations increased antibacterial effect of CAP.

\section{AUTHORS' CONTRIBUTIONS}

ACE was the principal investigator. PCU supervised the work/manuscript; COE suggested the topic, was also the mentor. JEO and KCC proof read the work/manuscript.

\section{ACKNWOLEDGEMENTS}

We are grateful to Affonne OJ and Ilodigwe $\mathrm{Eb}$ for their advices. Finally, we are grateful to Igboeme S, Amilo C, Offor C and Onah SU for their technological assistance.

\section{REFERENCES}

Asakhiors S, Angeloianni P, Schulpia KH, Stavridia JC. 2000. Protective effect of L- phenylalanine on rat brain acetylcholinesterase inhibition induced by free radical. Journal of Clinical Biochemistry, 33(2): 103-106.

Chambers HF. 2000. Protein synthesis inhibitors and miscellaneous antibacterial agents. In The Pharmacological Basis of Therapeutics, Brunton LL, Laso JS, Parker KL (eds). Goodman \& Gilman's. McGraw-Hill, New York; 1173-1182.

Cheesbrough M. 2002. District Laboratory Practice in Tropical Countries Part 2. Cambrige University Press: New York.

Chen J. 2005. Animal models for acquired bone marrow failure syndromes. Clinical Medicine Research, 3(2): 102108.

Chilaka KC, Unekwe PC, Ekechukwu AC, Ogamba JO. 2005. Management anemic effect chloramphenicol using amino acids on albino rats infected with 
Salmonella typhi. African Journal of Science, 6(1): 1385-1391.

Clark. M, Kumar P. 2011. Kumar \& Clark's Clinical Medicine $\left(7^{\text {th }}\right.$ edn). Saunders Elsevier: Edinburgh.

Cockburn F, Klien JO, Klien R. 1965. Chloramphenicol and L-phenylalanine therapy in experimental Klebsiella pneumoniae infection in mice. Proceeding of Society of Experimental Biological Medicine, 120: 611-614.

Daum RS, Cohen DL, Smith AL. 1979. Fatal aplastic anemia following apparen dose-related. Journal of Pediatrics, 94(3):403-406.

Dowling PM. 2006. Chloramphenicol, thiamphenicol, and florfenicol. In Antimicrobial Therapy in Veterinary Medicine $\left(4^{\text {th }}\right.$ edn), Giguere S (ed). Oxford Blackwell Publisher: Ames, Iowa.

Effiong GS, Ebong PE, Eyong EU, Uwah AJ, EkongUE. 2010. Ameliora of chloramphenicol induce toxicity in rats by coconut water. Journal of Applied Science Research, 6(4): 331- 335.

Esimone CO, Nworu CS, Ekechukwu AC, Awemu AG. 2007. Effect of phenylalanine and glycinle on some toxic effect of chloramphenicol. Scientific Research and Essay, 2(4): 105-111.

Falagas ME, Grammatikos AP, Michalopoulos A. 2008. Potential of old-generation antibiotics to adresscurrent need for new antibiotics. Expert Review of Anti Infective Therapy 6(5): 593- 596.

Fitton JE, Shaw WN. 1979. Comparison of chloramphenicol acetyltransferase variant in staphylococcus purification inhibitors studies and N-terminals sequence. Journal of Biochemistry 177(2): 575-582.

Fullers DG, Duke T. 2003 Antibiotics treatment for bacterial meningitis in children in developing countries. Annual. Tropical. Paediatrics, 23: 233253.

Froh M, Thur man RG, Wheeler MD. 2002 Molecular evidence for a Glycine -gated chloride channel in macrophage and leucocytes. Am J. Physiol. Gastrointestinal liver Physiol., 283(4) GB 5663.

Hishinuma FK, Izaki K. Takahashi H. 1970. Inhibition of incorporation L- alanine into uridine diphospho-N- acetylmuranic acid by glycine Journal of Agricultural and Biological Chemistry, 34(4): 655657.

Holt DE, Bajoria R. 1999. The role of nitroreduction and nitric oxide in toxicity of chloramphenicol. Human and Experimental Toxicology, 18(2):111-118

Hossam E, Mohammed AD, Wafara SZ, Moustafa AE, Mohamme. 2010. The role of Nigella Sativa in ameliorating Chloramphenicol induced tissue damage in Rats. Journal of Medicinal Plant Research, 5(2): 280- 288.

Ichiyama T, Zhao H, Catania A, Furukawa S, Lipton JM. 1999. Alpha- Melanocyte stimulating hormone inhibits NFkappaB activation and I kappaB alpha degradation in human glioma cells and in experimental brain inflammation. Journal of Experimental Neurology, 157(2): 359-365.

Ingall D, Sherman JD, Cockburn F, Klein R. 1965. Amelioration by ingestion of henylalanine of toxic effects of chloramphenicol on bone marrow. New England Journal of Medicine, 272: 180-185. 
Jacob T, Ascher E, Hingorani A, Kallakuri S 2003. Glycine prevents the induction of apoptosis attributed to mesenteric ischemia/reperfusion injury in a rat model. Journal of Surgery, 134(3): 457466.

Jeon YJ, Lee JS, Jeong HG. 1999. Induction of inducible nitric oxide synthase gene expression by Pokeweed mitogene. Chemico-Biological Interaction, 118(2): 113-125.

Manion CV, Hochgeschwender U, Edmundson AB, Hugli TE, Gabagliaz CR 2011. Dietary aspartylphenylalanine-1-methyl esters delays osteoarthritis and prevent associated bone loss in STR/ORT Mice. Oxford Journal of Medical Rheumatology, 50(7): 1244-1249.

McCurdy PR. 2011. Chloramphenicol bone marrow toxicity. JAMA and Archives Journal, 305(4): 329-423.

Minami M, Ando T, Hashikawa SN, Tori K, Hasegawa TN, Israel DA, Ina K, Kusugami K, Goto H, Ohta M. 2004. Effect of Glycine on Helicobacter pylori In Vitro. Journal of Antimicrobial Agents Chemotherapy, 48(10): 37823788.

Pongjit K, Ninsontia C, Chaotham C, Chanvorachote P. 2011. Protective effect of Glycine $\max$ and Chrysanthemum indicum extracts against cisplatin-induced renal epithelial cell death. Human \& Experimental Toxicology, 30(12): 1931-1944.

Rich M, Ritterhoff R, Hoffmann R. 1950. A fatal case of aplastic anemi following chloramphenicol (chloromycetin) therapy. Annals of Internal Medicine 33(6): 1459-1461.
Rosenberg A, Marcus O. 2008. Effect of Chloramphenicol on Reticulocyte $\Delta$ Aminolaevulinic Acid Synthetas Rabbits. British Journal of Haematology, 26(1): 79-83.

Ruef C, Blasser J. 2000. Miscellaneous antibacterial drugs: aminoglycosides chloramphenicol thiamphenicol; fluoroquinolones glycopeptides. In Meyeler's Side Effects of Drugs, Dukes MNG, Aronson JK (eds). Elsevier Sceinces: The Netheland; 848-885.

Sharma SP, Sharma J, Kanwar SS, Chauhan V. 2012. In vitro antibacterial and antimalarial activity of dihydrophenylalanine containing undecapeptides alone and in combination with drugs. International Journal of Antimicrobial Agents, 39(2): 146-152.

Senthilkumar R, Sengottuvelan M, Nalini N. 2004. Protective effect of glycine supplementation on level of lipid perioxidation and antioxidant emzyme in the erythrocyte of rat with alchohol induced liver injury. Journal of Biochemistry, 6(3): 96-105.

Smick KM, Condit PK, Proctor RL, Sutcher V. 2004. Fatal Aplastic Anaemia : An epidemiological Study of its relationship to the drug Chloramphenicol. Journal of Chronic Disease, 17(10): 899- 914.

Turton JA, Andrew CM. Harvard AC, Williams TC. 2002. Studies on the heamatoxicity of chloramphenicol succinate in the Dunkin Hartley guinea pig. International Journal of Experimental Patholology, 87(2): 101112.

Tse A, Brigle K, Tayor SM, Mogan LG. 1998. Mutation in the reduced carrier gene which confers dominant resistance of phenyalanine and glycine 
to $5,10 \mathrm{~d}$ ideazetetrahydrofolate respectively. J. Biol. Chem., 271(4): 5360.

Yolande AC, Lourdes G, Oncana S, Katya CD, Xochitl S, Ramirez G. (2011). Effect of glycine on lead mobilization ,lead induced oxidative stress and Hepatic toxicity. Journal of Experimental Pathology, 87(2): 101112.

Yin M, Zhong Z, Connor HD, Bunzendahl H, Fin WF, Rusyn I, Xiangli LJ. 2002. Protective effect of glycine on renal injury induced by ischemia reperfusion in vivo. American Journal of Renal Physiology, 3(8):122-130.

Zhou W, Gao T. 1997. The protective effects of phenylalanine on ischemiareperfusion injury in mouse heart. Acta Scientiarium Naturalium Universitiatis Pekinensis, 33(2): 203-210

Zhou JL, Huang YS, Dang YM, Zhang JP. 2005. Protective effect of glycine on hypoxic rat myocardial cell. Chinese Journal of Biochemistry, 21(5): 329332. 